\title{
DESTECENDO OS SILÊNCIOS DE UM MEMORIAL
}

\author{
UNWEAVING THE SILENCES OF A MEMORIAL
}

Luiz Carlos Leite ${ }^{1}$

\section{Resumo}

Nesse artigo, discute-se uma das possíveis maneiras de se produzir um pensamento sobre pedagogias nos campos da performance, teatralidade e artes como um todo, a partir dos procedimentos de uma prática pedagógica intitulada Desmontagem. Tal procedimento foi apresentado e experimentado no ano de 2013 na disciplina Pedagogia(s) do Teatro - práticas contemporâneas, no Programa de Pós-Graduação em Artes da Universidade Federal de Uberlândia-UFU, a partir da atuação da crítica de teatro cubana radicada no México, Profa. Dra. Ileana Diéguez, que trabalhou tal procedimento em diálogo com a prática artística dos pós-graduandos do Programa.

Palavras-chaves: Teatro, Pedagogia, Desmontagem, Dramaturgia

\section{Resumen}

En este artículo, analizamos una de las posibles maneras de producir un pensamiento acerca de las pedagogías en las áreas de rendimiento, la teatralidad y las artes como un todo, desde unos procedimientos de la práctica pedagógica titulada Desmontaje. Tal procedimiento fue presentado y experimentado en el año 2013 en la disciplina Pedagogía(s) del Teatro prácticas contemporáneas, en el Programa de Postgrado en Artes de la Universidad Federal de Uberlândia-UFU, de la ejecución crítica del teatro cubano arraigada en México, Profesora Dra. Ileana Diéguez, quien trabajó un procedimiento de este tipo en el diálogo con la práctica artística de estudiantes de posgrado en el Programa.

Palabras clave: Teatro, Educación, Desmontaje, Dramaturgia

\section{Abstract}

The present paper holds a discuss on the possible ways to produce a thought about pedagogies in the fields of performance, theatricality and arts as a whole, extracted from a pedagogical procedure entitled as Desmontagem (Disassembly). Such procedure was presented and experienced in the year 2013 in the subject: Theatre Pedagogy (s) - contemporary practices, at the Graduate Art Program in Uberlandia's Federal University -UFU. It was possible through the performance of the cuban theater critic from Mexico, Professor. Dr. Ileana Dieguez - who worked such procedure in dialogue with the artistic practices of graduate students in the Program.

Keywords: Theatre, Education, Disassembly, Playwriting

Em sua obra Des/tejiendo escenas, Ileana Diéguez, reúne reflexões desenvolvidas em torno das desmontagens como processo de trabalho. Ao fazer uma análise do conjunto dos textos desta obra, ela nos chama a atenção para o fato de que os mesmos eram "testemunhos, perguntas, reflexões, experiências e nenhuma certeza, nenhum método, nenhum saber $a$

\footnotetext{
${ }^{1}$ Universidade Federal do Estado do Rio de Janeiro - UNIRIO. Centro de Letras e Artes. Programa de PósGraduação em Artes Cênicas/ Universidade Federal de Uberlândia - UFU. Instituto de Artes. Programa de PósGraduação em Artes. Doutorado/DINTER 2013/2017. Orientadora Profa. Dra. Rosyane Trotta. CAPES. Dramaturgo e Técnico em Assuntos Educacionais na Universidade Federal de Uberlândia, MG.
} 
priori." (DIÉGUEZ, 2009, p.8). Esse indicativo é importante, pois aponta para a desmontagem não como uma metodologia aplicada, mas como reflexões, perguntas e experiências. Por isso, a desmontagem de um espetáculo pode ser identificada como um procedimento pedagógico e não um método.

Ao reunir textos que abordam diferentes experiências sobre práticas de desmontagens, Diéguez utiliza-se do brilhante artifício de compará-los a véus, ou seja, "os véus cobrem, porém também desvelam, descobrem, tornam visível o que parece que protegem” (DIÉGUEZ, 2009, p.8), de maneira que há uma intenção, uma busca em dar visibilidade a essas experiências através das palavras, ou seja, os textos reunidos em sua obra.

Ao fazer a desmontagem de um espetáculo o que está em jogo é um processo de investigação sobre o próprio processo de criação. É sempre uma nova criação, distinta da encenação original sobre a qual "se desmonta", onde se revela justamente esse processo de criação através do compartilhamento destes, não em sua totalidade, mas via escolhas e eleições daquilo que se entende por necessário à compreensão do processo criativo e não apenas do resultado final.

Ao problematizar o termo desconstrução, Diéguez chama a atenção para o implícito, afirmando ser esta uma prática política e filosófica, apontando seu uso dentro de um contexto estruturalista que permite uma evidenciação dos sistemas de poder nela contidos. Para isso, dialoga com a obra de Jacques Derrida no sentido em que este irá, a partir da estrutura da própria palavra desconstrução, implicar o significado de decomposição das próprias estruturas fixadas em modelos. Mas também, o termo desconstrução não seria para Derrida, a criação de um novo modelo pautado à simples redução de destruir de "reduzir-se a operações negativas: apesar do prefixo de” (DERRIDA, 2009, p.11). Assim, mais do que o sentido de destruir, estaria o de reconstruir de tornar visíveis os jogos da construção.

Acredito ser suficiente, nesse momento, a clareza do sentido da palavra desmontagem estar associada a esse processo do não destruir, mas sim tornar visível a construção, conforme nos apresentou Diéguez. Isso é de fundamental importância para o entendimento do sujeito que se coloca em presença revelando suas poéticas e mais do que isso, suas escolhas, recortes, suas opções na construção de um devir, de um processo artístico a ser desvelado e revelado também a seu próprio autor.

Quando eu dizia estar fazendo a desmontagem de um trabalho artístico, invariavelmente, as pessoas associavam a palavra a dois conceitos de processos. Diziam: "uma demonstração de trabalho" ou então se seria como uma "crítica genética". Nem uma nem outra! Apesar de dialogar com ambos os conceitos, é uma terceira “coisa". 
A própria pensadora Ileana Diéguez ao fazer a reconstrução da história do surgimento do termo desmontagem, reconhece sua imbricação às chamadas demonstrações de trabalho do Odin Teatret e de Eugênio Barba, na origem da palavra. Essas demonstrações de trabalho são conhecidas e apropriadas em diferentes graus de relação por grupos latino-americanos de teatro, como o Grupo Buendia (Cuba) e o Yuyachkani (Peru), dentre outros. Isso é importante, pois fará com que vários atores passem a apresentar além do espetáculo, também seu processo. Essa prática vai se configurando em diversos encontros, eventos e festivais, de maneira que, logo as demonstrações de processos cênicos começaram a ser chamados de desmontagens (década de 1990), onde para além de uma demonstração técnica, falava-se de experiências, das trajetórias dos grupos, desvelando o véu, tornando visível o que parecia estar guardado. E por que não seria a desmontagem de um espetáculo, por exemplo, uma demonstração técnica de trabalho? Porque mesmo partindo de uma obra de base é exatamente outro processo, outro espetáculo que surge, servindo esta, a obra de base, como ponto de reflexão, de alicerce para a construção de um novo processo, como um novo espetáculo e não apenas a demonstração de como se deu uma construção.

A desmontagem também "não é como a crítica genética", conforme alguns enunciaram em um primeiro instante ao ouvirem o termo. Apesar de no campo das artes, a Crítica Genética aparecer, com o intuito de analisar os indícios da construção de uma obra, mapeando as primeiras anotações e ideias do artista e o desenvolvimento do processo, ela pode também ser chamada de uma "genética textual", pois:

O interesse da Crítica genética está voltado para o processo criativo artístico. Tratase de uma investigação que indaga a obra de arte a partir de sua fabricação, a partir de sua gênese. Como é criada uma obra? Esta é sua grande questão. (SALLES, 1992, p. 17).

Aqui há uma confluência, mas é preciso destacar que, mesmo levando em consideração a subjetividade do(s) autor(es), observa-se a partir de um documento, de um texto. Na desmontagem são os próprios autores/atores quem irão revisitar suas experimentações, para além das "marcas" e "traços" contidos em um material textual, por exemplo, e gerar um novo produto que é processo, uma recriação.

\section{O desafio da desmontagem.}

A proposta de "desmontar" um trabalho artístico foi um desafio. A primeira questão

que me surgiu foi a de como fazer uma desmontagem a partir da dramaturgia de um 
espetáculo encenado? A escolha recaiu sobre o espetáculo Memorial de silêncios e margaridas $^{2}$, obra que depois de concluída, passei a assinar sua autoria em conjunto com o atuador Narciso Telles, mas à qual deveria ser atribuído mais um sentido de autoralidade (TROTTA, 2008) em referência às especificidades do processo de criação realizado de maneira coletiva, onde nos utilizamos de diversos materiais de investigação como obras literárias, relatos jornalísticos, fotografias, canções e depoimentos que foram apropriados e, posteriormente partilhados em sala de ensaio.

Ao responder o desafio de promover a desmontagem de um espetáculo já encenado, foi preciso revisitar uma prática de trabalho que, foi se configurando com a prática do fazer, sem que, no entanto, houvesse uma reflexão anterior sobre esse mesmo processo. Esse é no meu entender, o grande ganho desse procedimento, pois exige que se promova essa reflexão e um novo ordenamento dos elementos que foram se configurando a partir do exercício prático e das necessidades que foram surgindo conforme o avanço dos trabalhos. Um aspecto a ser destacado nesse momento foi o de que entendi ser necessária a presença do atuador em cena no processo de desmontagem da dramaturgia do espetáculo, pois a própria dramaturgia havia sido construída juntamente com o atuador e, não havia como dissociar sua evidenciação naquele momento que era orgânico ao próprio procedimento de criação, o que corrobora a ideia de uma construção partilhada.

Quando o atuador/diretor ${ }^{3}$ fez o convite para uma contribuição na construção da dramaturgia do espetáculo, um aspecto foi evidenciado: havia a anterioridade de uma pesquisa em seu Pós-doutoramento, onde este estava trabalhando a questão da(s) violência(s), fosse ela de raça, gênero ou etnia, na América Latina, além de todas as outras formas de violência exercidas pelos regimes ditatoriais que marcaram a vida das pessoas nessa região, nos anos de 1960, 1970, sobretudo, e início dos anos de 1980.

O convite veio acompanhado de um livro de Eduardo Galeano (2005) que relata várias histórias de pessoas comuns, que sofreram uma diáspora na América Latina durante o chamado "anos de chumbos". Não apenas a violência e intolerância, o que não é pouco, cometidas pelos regimes ditatoriais são relatados, mas a violência da ruptura com o cotidiano dos afazeres, dos filhos, das pessoas amadas, enfim, o conflito de estar despojado de suas

\footnotetext{
${ }^{2}$ Memorial de silêncios e margaridas estreou na cidade de Uberlândia-MG, no ano de 2011. Ficha Técnica: Dramaturgia: Luiz Carlos Leite e Narciso Telles. Atuação: Narciso Telles. Direção: Mara Leal. Iluminação: Camila Tiago. Operadora Luz: Marcela Prado. Concepção Som: César Lignelli. Orientação Vocal: Dirce Helena ${ }^{3} \mathrm{O}$ atuador/diretor, Narciso Telles fez o convite para contribuir na construção dramatúrgica do espetáculo em um momento em que este já havia iniciado alguns ensaios. Mais adiante no processo irá também convidar a atriz Mara Leal para fazer a direção.
} 
vidas para sobreviver, fugindo às atrocidades do terror. Esses personagens de Galeano nos ofereciam uma série de imagens sobre as quais poderíamos pensar as cenas. Partimos assim em busca de vários outros autores durante a construção do espetáculo Memorial..., quando pudemos perceber a recorrência dessa temática. Pareceu-nos que após os períodos de ditadura e barbáries como os extermínios em massa, há uma necessidade de se falar sobre isso, seja no sentido jurídico, de reparação, seja no sentido de dar voz àqueles que foram silenciados. Acredito que este foi nosso posicionamento diante do trabalho cênico a revelar-se apenas no instante da desmontagem.

Partimos em busca dos testemunhos, pois mesmo que estes não pudessem ser aceitos como instrumentos plenos de verdade, ao mesmo tempo não era possível negar-lhes um núcleo de verdade. Procuramos então trabalhar a sua possibilidade enquanto uma dramaturgia do tempo presente, pois através deles foi possível ler-se imagens e, toda imagem é dialética.

Os testemunhos e o teatro utilizam-se dos corpos, mesmo porque a dramaturgia é posterior aos depoimentos, mas sua opção pelos depoimentos é anterior e como aponta Barthes: "A teatralidade é o teatro menos o texto, uma espessura de signos e de sensações que se edifica no palco...” (BARTHES, 2006, p.48). No início dos trabalhos em sala de ensaio, dialogamos com Miguel Rubio, diretor do grupo peruano Yuyachkani, que nos fez uma indagação poética, sobre os possíveis papéis do teatro em tempos de violência política, através de um texto que foi escrito e montado no contexto da guerra suja peruana, ou chamado período Fujimori, nas décadas de 1980 e 1990. Trata-se de Adiós Ayacucho ${ }^{4}$ que narra a trajetória de um dirigente camponês morto na cidade de Ayacucho, no Peru, esquartejado por uma ação militar por considerá-lo subversivo. O próprio morto narra a sua viagem para a capital, com o fim de recuperar a outra metade do seu cadáver. Não há exatamente o testemunho dos mortos, mas uma fala em nome deles, uma reflexão sobre o corpo ausente, porque ao assassinado é permitida a plenitude da experiência, mas ao mesmo tempo, a negativa de seu testemunho.

A partir de uma imagem geradora, comungada entre ator e dramaturgo, através de Miguel Rúbio, do escritor Eduardo Galeano, estávamos diante de inúmeras histórias de pessoas comuns que procuraram resistir à intolerância, sobreviver, nem que fosse justamente pelo direito desse simples cotidiano. Nesse instante, diante de um mergulho na diversidade das narrativas que os autores nos apresentavam, sem preocupação com qualquer tipo de uma verdade histórica, a ideia central do espetáculo estava definida. Iríamos contar a história

\footnotetext{
${ }^{4}$ Narração Júlio Ortega em versão teatral de Miguel Rubio.
} 
dessas pessoas comuns, não para resgatar, mas para dizer que algo aconteceu e, lembrar no sentido de evitar que se repita. Selecionamos fragmentos a partir da subjetividade de cada um e iniciamos um saudável e contínuo processo de convencimento entre ambos e depois também com a diretora, a partir das histórias que mais nos sensibilizavam.

Apresentei uma ideia inicial de título ao possível espetáculo. Era: “A vocês que se foram! (título provisório ago/2009)”. A partir do título pode-se observar que o uso do pronome pessoal "vocês" denota, além do seu emprego no plural, a intenção de trazer para a cena do presente os sujeitos aos quais se pretendia fazer uma espécie de "homenagem", através de uma rememoração àqueles que foram assassinados pelas ditaduras militares na América Latina. O título atual do espetáculo, Memorial de silêncios e margaridas, passou por diversas reelaborações, sem que, no entanto, houvesse a perda dessa intenção original.

Cada uma das cenas também sofre um contínuo processo de experimentação, escrita, reconfiguração e reescrita. Assim, nessa primeira versão, de agosto de 2009, a Cena 1 estava, conforme registros do autor, proposta da seguinte maneira:

Cena 1 - a morte do general - (Em cena - palco nu - cadáver deitado - pode ser nи ou coberto por tecido branco - imagem de um corpo no necrotério. Leve foco de luz que se acende lentamente sobre ele, aumentando de intensidade. Não há pressa).

A imagem geradora dessa cena era a de apresentar um antigo general, personagem das ações de torturas, mortes e "desaparecimentos" que, após algum tempo, já quando de sua morte, passará a recordar através de narrativas em tempo presente, suas memórias do passado, como alguém que "produziu" diversos cadáveres, e agora também é um deles. A proposta inicial permaneceu; o aqui e agora e a narrativa do acontecido. Nota-se também a intenção da ausência de cenário - palco $n u$ - afirmando a intenção de um foco de cena na imagem: um corpo a revelar-se. Em uma etapa seguinte, registrada na versão de fevereiro de 2010, a proposta dessa mesma cena era também, a de que se revelasse o nome de presos políticos desaparecidos durante a ditadura militar no Brasil (1964-1985) conforme registro de uma terceira versão do texto: Cena 1: - bem-vindos - (no chão - projetados - ou qualquer outra forma - começam a desfilar os nomes dos mortos durante a ditadura no Brasil - Enquanto público entra: Ator está em cena - sentado diante de uma máquina de escrever, cantando...). Apesar de uma aparente cena diferente da proposta anterior, ela já se configurava como expressão daquela imagem inicial do "a vocês que se foram". A partir da sala de ensaio surgia uma teatralização de forma aberta, não presa a um texto. Por fim, na fixação da escrita atual, a mesma cena tem a seguinte indicação: Cena 1. (Em cena - ator recebe o público cantando a música "Canção da despedida" de Geraldo Azevedo!) 
Apenas a didascália da cena é aqui apresentada e não o texto, pois o objetivo é o de procurar mostrar a trajetória de construção da mesma ao longo do processo de teatralização. As imagens geradoras do espetáculo permanecem, só que agora de maneira mais organizada devido a esse contínuo perguntar-se sobre o que queríamos dizer. O general morto retornará, agora em uma cadeira de banho e suas vítimas desfilarão suas lembranças das torturas, ou sua negativa de retorno, daí o uso do termo "silêncios" no título atual. A reconfiguração da cena é fruto da proposta do atuador em experimentar a cadeira de banho, a máquina de escrever, as canções, enfim, um processo de colaboração, no qual o dramaturgo interfere na cena e o ator na escrita dessa cena.

A seguir, apresento um simples exemplo de como houve uma participação direta do ator, fornecendo estímulos também literários, além das próprias improvisações e exercícios em sala de ensaios. Em correio eletrônico, recebi a seguinte mensagem do atuador: "Luiz, vj esta matéria. "Vala dos sem nome" poderia ser um bom titulo não?! Recebi o livro sobre o Fleury e to lendo das mulheres torturadas. É um tema bem pesado". Tratava-se de uma matéria em jornal sobre o cemitério Dom Bosco, conhecido como cemitério de Perus que recebia cadáveres de pessoas não identificadas, indigentes e vítimas da repressão, ou seja, pessoas enterradas sem nome e sem reconhecimento. Os mortos pela ditadura militar no Brasil foram ocultados pelos assassinos em um cemitério de mendigos e indigentes. Em outros países da América Latina foram atirados ao mar, outros queimados... E as mães, esposas, pais e esposos que querem enterrar seus filhos, companheiros, irmãos... Essas questões atravessavam a proposta de encenação e foram sendo incorporadas em diferentes graduações, trazidas diversas vezes pelo atuador, como nesse exemplo e, não propostos pelo dramaturgo. Os legistas, as desovas de corpos, os órgãos de repressão, os refugiados, as torturas... todos esses elementos passaram a fazer parte da proposta do espetáculo em construção.

Seria cansativo enumerar aqui os outros livros, filmes, músicas, fotografias, visitas ao Memorial da resistência ${ }^{5}$ e depoimentos que foram utilizados como material de base na construção de uma "escritura articulada e colaborativa entre os âmbitos verbal e cênico, corporal e imagético, vocal e sonoro" (DA COSTA, 2009, p. 33). Mas, no exercício da desmontagem do espetáculo fomos apresentando os três momentos do processo de construção

${ }^{5}$ O Memorial da Resistência é uma instituição dedicada à preservação de referências das memórias da resistência e da repressão políticas do Brasil republicano (1889 à atualidade) por meio da musealização de parte do edifício que foi sede, durante o período de 1940 a 1983, do Departamento Estadual de Ordem Política e Social de São Paulo - Deops/SP, uma das polícias políticas mais truculentas do país, principalmente durante o regime militar. (Site: http://www.memorialdaresistenciasp.org.br/) 
da escritura cênico-dramatúrgica, quais sejam; o tema gerador, os nomes dados como núcleo de cada uma das cenas e, as próprias cenas com suas reescritas, sempre dialogando com as diversas modalidades discursivas utilizadas na proposta da teatralização.

Evidenciamos que as narrativas fragmentadas vieram de outros autores - livros e depoimentos - que a espacialidade configurou-se, sobretudo, a partir das imagens das celas e dos "porões da ditadura", enfim, fomos desvelando os procedimentos utilizados até a etapa presente do trabalho. Muitas questões revelaram-se a partir desse exercício do pensar sobre o próprio processo, gerando assim outra encenação sobre a obra de base que se "desmonta".

Acredito que o grande ganho nesse procedimento, foi a revelação de nossa escritura a partir de uma teatralidade que estava inscrita em nossa experiência, na qual a alteridade de cada uma das vozes presentes no processo, pode ser dispersada na subjetividade dos diversos personagens, através de seus corpos e suas vozes.

Bibliografia

BETTO, Frei. Batismo de sangue; os dominicanos e a morte de Carlos Marighella. Rio de Janeiro: Civilização Brasileira, 1982.

DA COSTA, José. Teatro contemporâneo no Brasil: criações partilhadas e presença diferida. Rio de Janeiro: 7Letras, 2009.

DERRIDA, Jacques. Carta a un amigo japonés. In: El tiempo de una tesis. Desconstrucción e implicaciones conceptuales. Barcelona: Projecto A, 1997.

DIÉGUEZ, Ileana. Des/tejiendo escenas: desmontajes: processos de investigación y creación. México: Instituto Nacional de Bellas Artes y Literatura: Centro Nacional de Investigación, Documentación e Información Teatral Rodolfo Usigli: Universidad Iberoamericana, 2009.

GALEANO, Eduardo. Dias e noites de amor e guerra. Porto Alegre: L\&PM, 2005.

SALLES, Cecília Almeida. Crítica Genética - Uma introdução. São Paulo: Editora da PUC, 1992.

SOUZA, Percival. Autópsia do medo: vida e morte do delegado Sérgio Paranhos Fleury. São Paulo: Editora Globo, 2000.

TROTTA, Rosyane. Autoria Coletiva no Processo de Criação Teatral. 2008. Tese (Doutorado) Centro de Letras e Artes da UNIRIO. Rio de Janeiro. 
Recebido em 03/04/2014 Aprovado em 01/06/2014 Publicado em 31/07/2014 